\title{
Shoot organization in the seagrass zostera noltif. implications for space occupation and plant architecture
}

Received: 18 February 2005/ Revised: 31 July 2005/ Accepted: 13 September 2005/Published online: 9 November 2005

(C) Springer-Verlag and AWI 2005

\begin{abstract}
The growth pattern of the seagrass Zostera noltii is described through the analysis of the shoot primordium organization within different shoot types using optical and scanning electron microscopy. Both histological approaches showed that $Z$. noltii shoots are organized by a successive repetition of a unit named "phytomer" (shoot primordium, node, internode, root, sheath and leaf), in resemblance with the shoot structure described for land grasses. This study showed that differences among shoot types are determined by two factors: (1) the presence or absence of some of the fundamental parts (mainly shoot primordium) in the "phytomer", (2) the evolvement stage of these elements. The branching of $Z$. noltii was limited by shoot structure and shoot primordium arrangement; in the "natural" branching pattern the first axillary shoot branched opposite to the previous branch. Simulation of the topology of a $Z$. noltii plant using the "natural" branching pattern, and its opposite one, with two different branching angles for each pattern, showed that the reduction in the branching angle notably decreases the colonizing efficiency (ca. $25 \%$ from 90 to $45^{\circ}$ ). Changes in the timing of shoot primordium development and/or release, and the optimization of the branching angle in response to external forcing (light, nutrients, density, etc.) may elucidate species-specific differences and colonization strategies with respect to abiotic conditions.
\end{abstract}

Keywords Clonal growth · Plastochrone interval · Branching angle $\cdot$ Histology $\cdot$ Productivity

Communicated by K. Lüning

This manuscript is dedicated to my first son (Fernando G. Brun Selma) who was born in August of this year.

F. G. Brun $(\bowtie) \cdot$ A. Pérez-Pastor · I. Hernández

J. J. Vergara · J. L. Pérez-Lloréns

Dpto. de Biología, Área de Ecología,

Facultad de Ciencias del Mar y Ambientales,

Universidad de Cádiz, 11510 Puerto Real, Cádiz, Spain

E-mail: fernando.brun@uca.es

Tel.: + 34-956-016028

Fax: + 34-956-016019

\section{Introduction}

Seagrasses are clonal plants that have colonized successfully shallow marine environments through a variety of morphologic and metabolic adaptations. A noteworthy outcome of this clonal nature is the highly ordered growth programme throughout a regular addition of modules (i.e. a piece of rhizome with a bundle of attached leaves and the corresponding roots). The extent to which clonal growth patterns are altered in response to environmental stimuli (i.e. phenotypic plasticity) may influence the plant ability to evolve under favourable conditions and to avoid the unfavourable ones (Slade and Hutchings 1987; Hemminga and Duarte 2000). Morphological and/or architectural variability may be a symptom of the high phenotypic plasticity of seagrasses to cope with stressful and changing environments where they thrive (Duarte 1991; Hemminga and Duarte 2000; Nelson 2000).

The large architectural diversity in terrestrial plants is the result of a variety in growth patterns of terminal, intercalary and lateral meristems (Sussex and Kerk 2001). Although meristematic growth and its fate are controlled by genetic and hormonal signals (Evans and Barton 1997; Nelson 2000; Berleth and Sachs 2001), little information exists about the molecular mechanisms underlying the morphological and/or plant architectural features driven by environmental changes. In seagrasses, despite the existence of some descriptive information on architecture and morphology (Den Hartog 1970; Tomlinson 1974; Peralta et al. 2000) and even on module ultrastructure (Kuo and Cambridge 1978; Tomlinson and Posluszny 1978; Tomlinson 1982), basic information on what determines the fate of individual meristems, the resulting architecture, and module spreading is still lacking.

Previous studies (Brouns 1987a, b; Marbá and Duarte 1998; Molenaar et al. 2000) showed that the spreading of seagrass clones could be simulated on the basis of their own growth rules and the percentage of rhizome branching. In these studies, the main factor controlling 
the seagrass spread (i.e. branching) is still considered as an unknown process, and it is taken as a stochastic phenomenon (measured as percent of branch node ${ }^{-1}$ ). However, branch formation is species-specific and has a strong seasonal and site-specific dependence. That is, branching frequencies are highest in short-leaved seagrass species (Duarte and Sand-Jensen 1990; Marbà and Duarte 1998), especially during spring-summer and in those individuals occurring at the edge of a meadow (Brun et al. 2003b). This suggests that seagrasses may optimize their branching pattern and meristem development with respect to abiotic conditions. However, this topic has been poorly studied, despite its importance for the spreading of seagrasses and the implication in its ecology.

In terrestrial species, particularly for grasses and cultivable species, a "leaf appearance" approach is used to determine the branch (tiller) development. For example, in some models branching is calculated from the leaf appearance rate of the mainstream and/or site filling (Bone et al. 1990; Neuteboom and Lantinga 1989; Bos and Neuteboom 1998). However, construction of a similar general model for seagrasses is not feasible yet since basic histological and evolvement information is not available.

A better knowledge of the meristematic-mediated processes in seagrasses is essential-(1) to understand how branching pattern and meristem development is optimized in response to abiotic conditions, (2) to understand which processes control spreading of clones, and (3) to provide useful information for future developments of predictive dynamic models for the spatially explicit growth. In this context, the goals of this study were: (1) to examine the shoot organization including meristems and shoot primordium disposition in the seagrass $Z$. noltii by using optical and scanning electron microscopy (SEM), (2) to describe its growth pattern and (3) to evaluate the ecological significance of such organization.

\section{Materials and methods}

Specimens of the seagrass Z. noltii Hornem. were collected from an intertidal muddy bed at Los Toruños, a salt marsh ecosystem of $773 \mathrm{Ha}$ situated in the Cadiz Bay Natural Park $\left(36^{\circ} 30^{\prime} \mathrm{N}, 6^{\circ} 10^{\prime} \mathrm{W}\right.$ ) (see Brun et al. 2003b; Pérez-Lloréns et al. 2004 for further information). Plants were transported to the laboratory in an ice-chest and rinsed carefully with seawater. Shoots were considered as a cluster of leaves placed in the same node (from a macroscopic point of view), and were sorted into three categories: apical or terminal (shoots showing apical dominance and horizontal rhizomatic growth), lateral (shoots arising from the axils of the rhizomatic leaves) and single small (short shoots stemming from an older or completely decomposed rhizome system) (Brun et al. 2003b) (Fig. 1).

For optical microscopy, tissues were fixed for 5 days in formaldehyde $(4 \% \mathrm{v} / \mathrm{v})$ and embedded in paraffin or historesin (Technovit 7100, Heraeus Kulzer). The latter technique was used in those shoots where the tissue was too hard to be sliced using paraffin. Sagittal and
Fig. 1 Z. noltii. Major morphological features in a $Z$. noltii plant

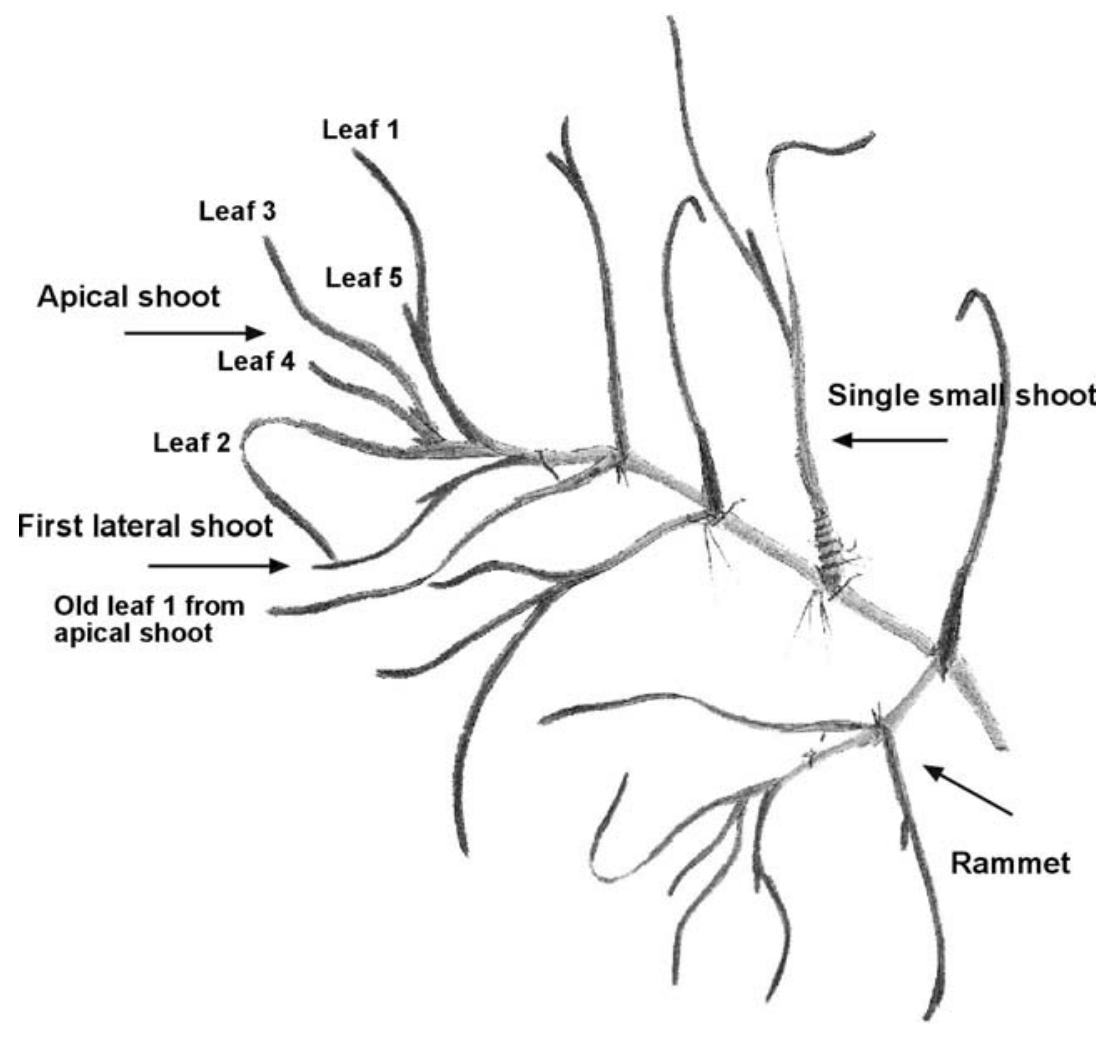


transverse sections (4 $\mu \mathrm{m}$ thick) were obtained and stained with hematoxylin-eosin (paraffin inclusions) or toluidine blue ( $\mathrm{pH}$ 9.4) (for historesin inclusion) (Bancroft and Stevens 1990). A digital camera (Olympus C4040) was used to photograph the sections. For SEM, tissues were cut using a razor blade $1 \mathrm{~h}$ before the microscopy session and washed in distilled water to avoid salt formation. SEM yielded detailed pictures using fresh samples, reducing its manipulation. Low vacuum mode was used to make the SEM photographs in a Quanta 200 microscopy.

In order to test the ecological relevance of the branching pattern and angle, hypothetical $Z$. noltii network topologies was constructed. For network building, different branching patterns and branching angles have been used, taking into account the range of variability for branching angle recorded in this species $\left(59 \pm 22^{\circ}\right.$, mean $\pm \mathrm{SD}$; range $12-150^{\circ} ; n=306$; Brun et al., unpublished), and the opposite branching pattern recorded (see Results section). Therefore, the following were simulated: (1) the branching pattern described in this paper ("natural" branching) at $90^{\circ}$ and (2) $45^{\circ}$ branching angles, (3) the opposite branching pattern at $90^{\circ}$ and (4) $45^{\circ}$ branching angles. This clonal network does not consider an exclusion area where two shoots cannot be placed (as in the field occurs) or other acclimation processes (e.g. branching restriction in highdensity areas). Moreover, it is assumed that branching occurs in all nodes. All pictures were drawn using the same number of nodes and branches, which were arranged at the same distances.

\section{Results}

Sagittal sections of apical shoots showed a zigzag (alternate) distribution of the axillary shoots, with a $180^{\circ}$-angle disposition in relation to the preceding one (Fig. 2). Leaves (L) no 1-4 belonged to the apical shoot (Fig. 1) while L-5 was the first visible leaf of the growing axillary shoot coated by the sheath of the apical leaves. Rhizome nodes were clearly visible and connected to the axillary shoot whereas internodes showed little development inside the apical shoots. Moreover, a direct relationship between shoot primordium developmental state (measured as the number of leaf primordia in each axillary shoot) and its distance from apical meristem was observed (Fig. 2).

Transverse sections through the apical shoot (including the second lateral shoot) from node (Fig. 3a) to the leaves (Fig. 3f), showed a clustered disposition of leaves within the shoot: the sheath of the oldest leaf was enveloping the other leaves and likewise successively. The first leaf of the axillary shoot (L-5) also grew sheltered by the sheath of the oldest leaf (L-1). Sheath developed only in the two oldest leaves of the apical shoot (L-1 and L-2) and the oldest leaf (L-5) of the first lateral shoot.

Transverse and sagittal sections of lateral shoots revealed a similar organization to that of apical shoots,
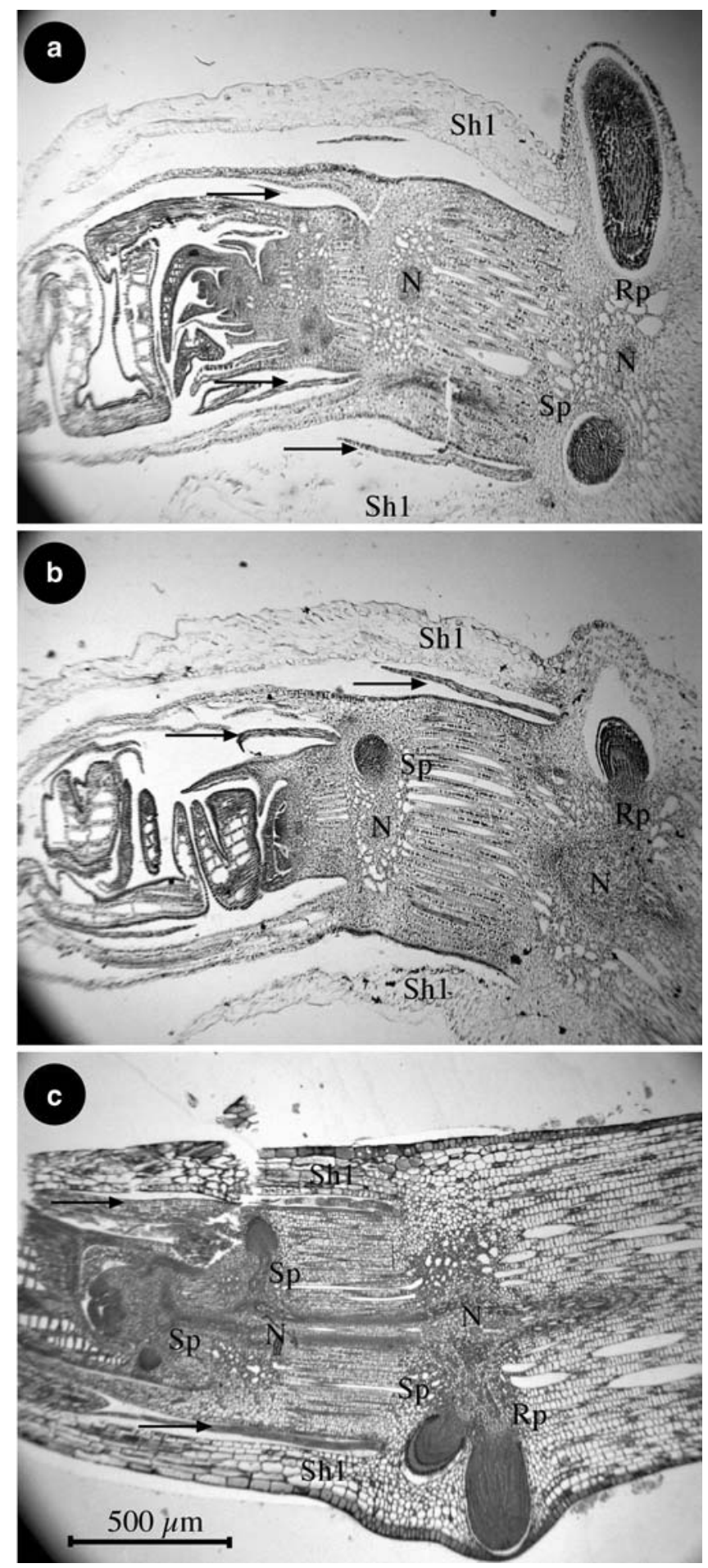

Fig. 2 Z. noltii. Sagittal sections of apical shoots. Pictures $\mathbf{a}$ and $\mathbf{b}$ are from the same apical shoots at different depths. Arrows indicate the first leaf of the shoot primordium (L-5); Sh1 is the sheath of the first apical leaf; $S p$ is the shoot primordium; $R p$ is the root primordium; $N$ is the node

but with a lower developmental grade (not shown). Axillary shoots grew alternating at the base of the leaf lateral shoot. The closer the position to the rhizome (the farther from the apex), the higher the developmental status. 

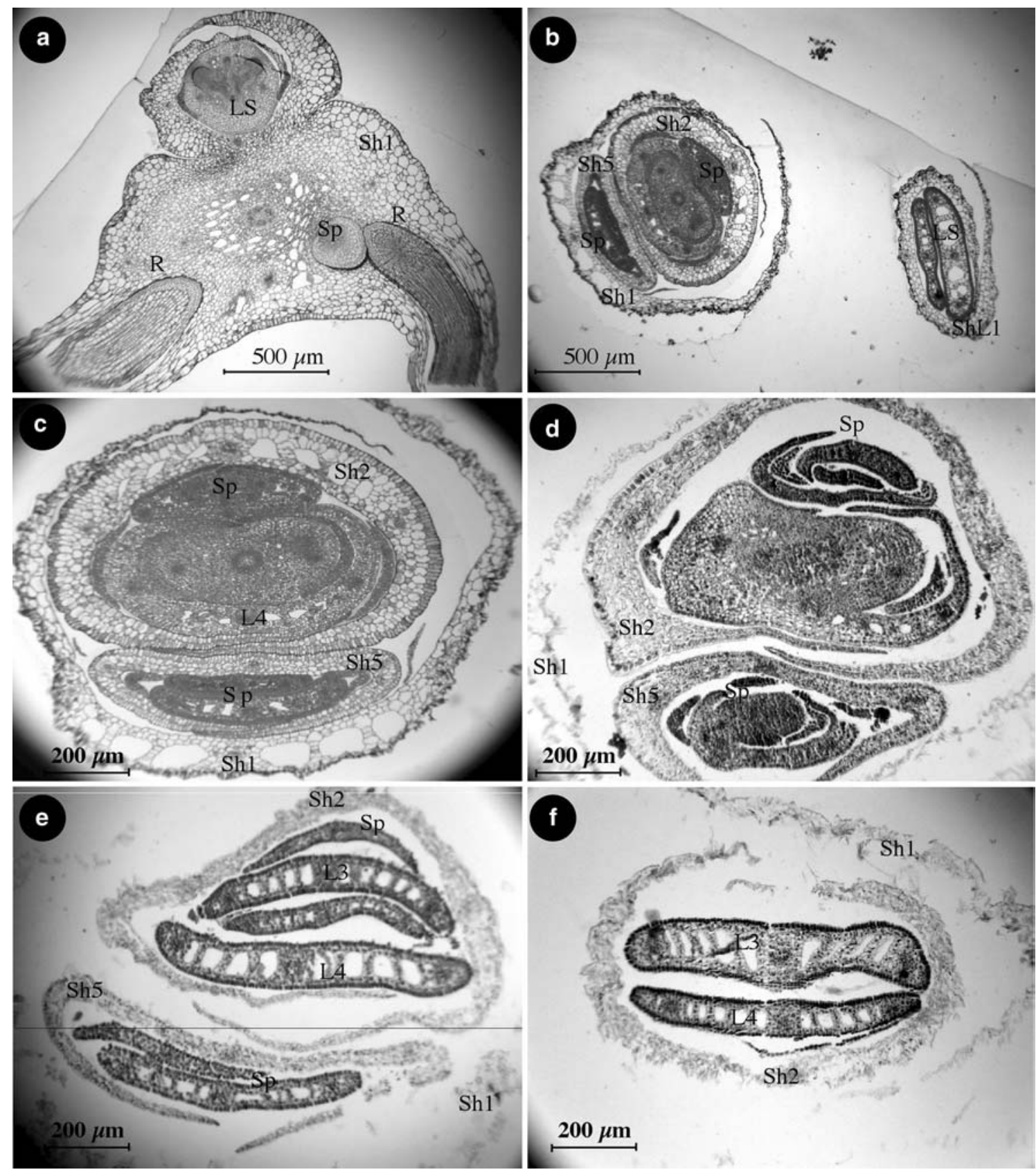

Fig. 3 Z. noltii. Transverse sections through an apical and first lateral shoots. Sections were done at different depths within the shoot, from node (a) upper to leaves (f). Shl is the sheath of the oldest leaf (L-1) in the apical shoots; Sh2 is the sheath of L-2 in the

Transverse section through single small shoots revealed the same clustered nature as described for apical and lateral shoots, with the sheath of the L-1 coating the remaining leaves including the first leaf from the axillary shoot (L-5) (Fig. 4a-c). The shoot primordium was also coated by the sheath of the L-2. Sagittal section of single small shoots showed an alternate distribution of axillary shoots above the L-1. Rhizome nodes underneath L-1 lacked shoot primordia, suggesting that axillary shoot died (or aborted) after formation (Fig. 4d, e). Internode development was also atrophied resulting in the typical

apical meristem; $S h 5$ is the sheath of the first leaf (LF) of the future lateral shoot; $S h L 1$ is the sheath of the old leaf 1 in the first lateral shoot; $L S$ is the first lateral shoot; $L_{n}$ is the leaf number from apical shoot; $S p$ is the shoot primordium; $R$ is the roots

morphology of this shoot type, that is, short internodes with numerous nodes (Fig. 4e). Consequently, this shoot category can be considered as a later evolvement stage in the lateral shoots' life-history, that is, when a lateral shoot does not branch or does not produce any new viable shoot primordium in the produced nodes.

The SEM images revealed similar structures to those described proviously. The sheath of older leaves wrapped up the youngest ones and so on in a cluster-like pattern (Fig. 5a, b) in apical and lateral shoots (transversal orientated). Axillary shoots, protected by the leaf sheath of 

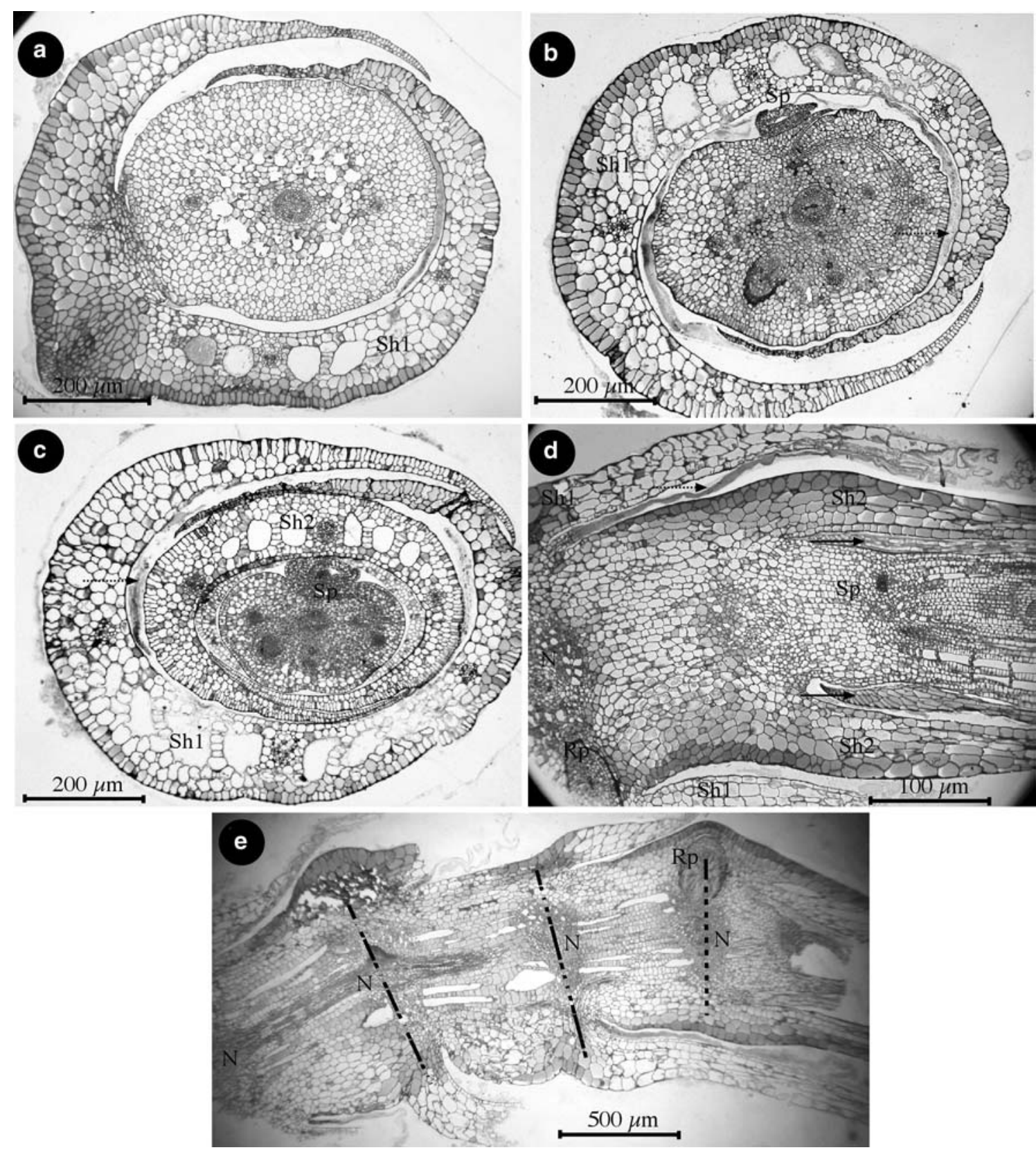

Fig. 4 Z. noltii. Transverse (a, b, c) and sagittal (d, e) sections through single small shoots. Sections $(\mathbf{a}, \mathbf{b}, \mathbf{c})$ were done at different depths of a single small shoot, from node (a) to leaves (c). Shl is the sheath of the oldest leaf of a single small shoot; Sh2 is the sheath of L-2 of a single small shoot; $S p$ is the shoot primordium; $N$ is the node; $R p$ is the root primordium the previous leaf, arose from this bottom (Fig. 5c, d; sagittal-orientated). Axillary shoots were absent in nodes of the single small shoots indicating a likely death (abortion) just after their formation (Fig. 5e; sagittalorientated).

Both histological approaches showed that $Z$. noltii shoots seem to be arranged by a successive repetition of a unit composed by node, internode, roots, axillary shoot, sheath and leaf. This arrangement has been named "phytomer" in resemblance with the shoot structure described for land grasses (Briske 1991; Nelson 2000).
Histology showed that the branching pattern of $Z$. noltii is constrained by the shoot organization and axillary shoot arrangement. That is, the first axillary shoot branches in the opposite direction of the previous branch (see Fig. 7A for "natural" branching pattern). It was checked in field samples, where branching direction was monitored for more than 100 plants, rendering final results where all the plants followed this branching pattern (data not shown).

Figure 6a-e shows the proposed growth model for $Z$. noltii derived from plant growth monitoring, whereas the schematic model obtained after successive additions 

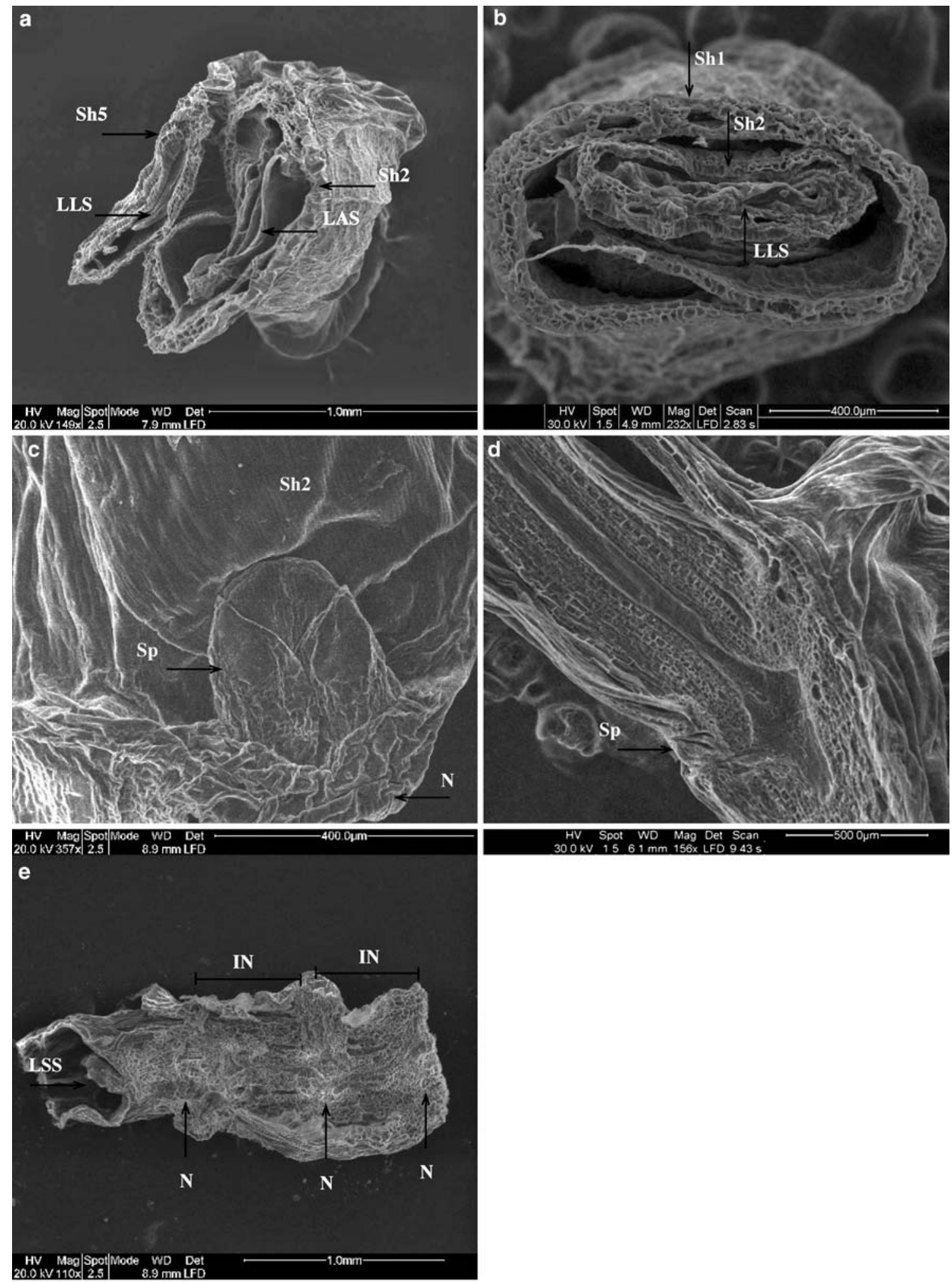

Fig. 5 Z. noltii. SEM of apical (a, c, d) lateral (b) and single small shoots (e). The sheath of L-1 of apical shoot was previously eliminated to allow photograph of shoot primordium. Sh1 is the sheath of the oldest leaf; Sh2 is the sheath of L-2; $S p$ is the shoot

primordium; $N$ is the node; $I N$ is the internode; $L A S$ are the leaves of the apical shoot; $L L S$ are the leaves of the lateral shoot; $L S S$ are the leaves of the single small shoot 
a

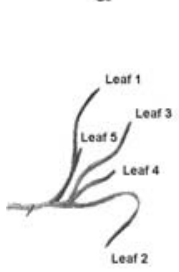

b

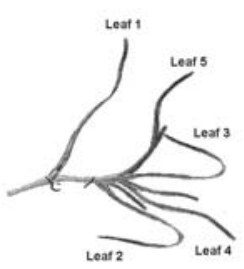

c

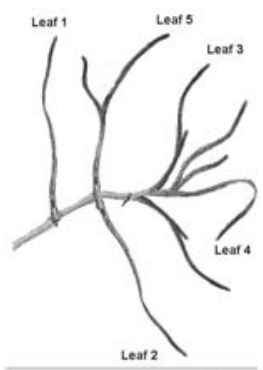

Symbols
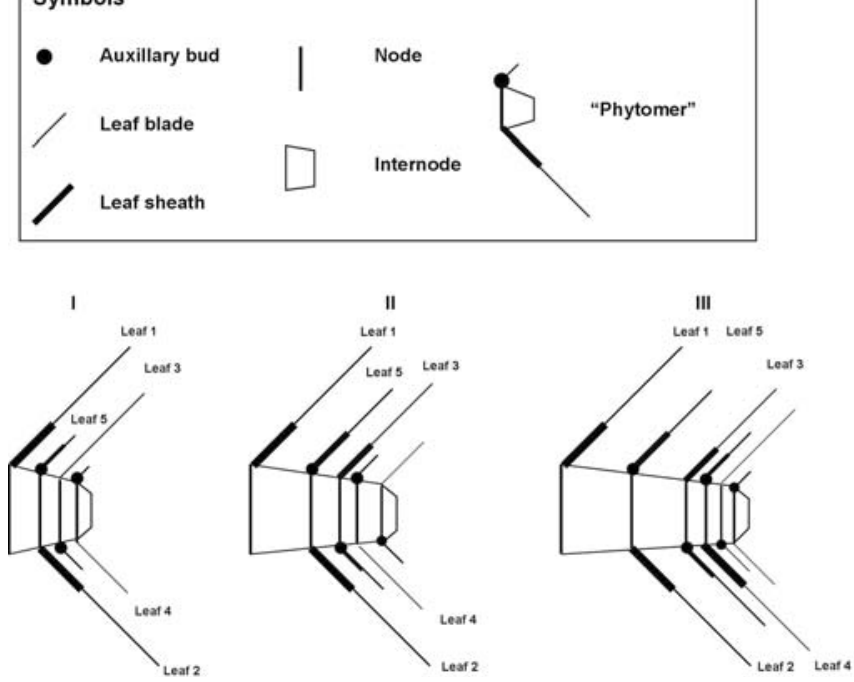

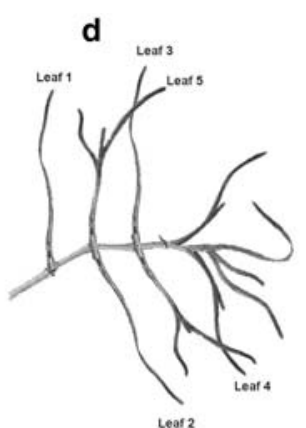

e

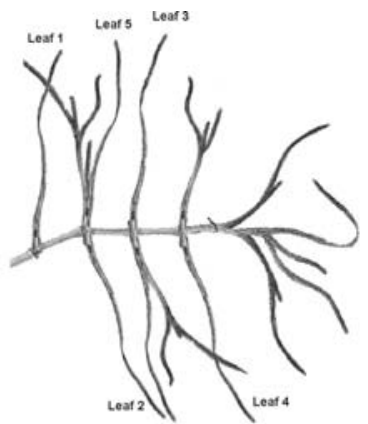

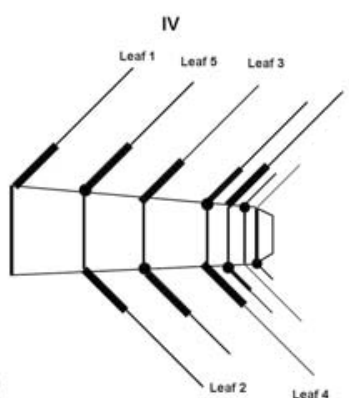

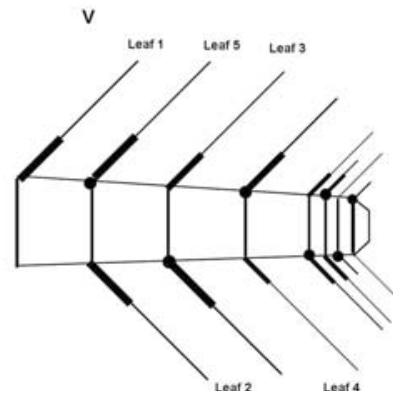

Fig. 6 Z. noltii. Proposed schematic growth model for the seagrass $Z$. noltii. Each step corresponds to an apical plastochrone interval $(P I-A)$. Figures with roman numbers show the proposed model using the "phytomer" structure (see text for further information). Symbols used in the model are explained in the inset square of "phytomer" units is illustrated in Fig. 6i-v. The latter model starts from an apical shoot with three complete "phytomers" and one "phytomer" without shoot primordium. Each phytomer addition corresponds to a plastochrone interval in the apical shoot $(P I-A)$ and with the production of a shoot primordium and a new leaf (L-5). Rhizome growth takes place during one $P I-A$. For simplicity, in the schematic model (Fig. 6i-v) the development of the older axillary shoots (i.e. growth of new leaves and shoot primodum) is not illustrated, as it is showed in Fig. 6a-e (development of the lateral shoots). Once the PI-A elapsed, a new "phytomer" is produced in the apical shoot (new young leaf, L-4) and a new internode grows sundering the oldest "phytomer" (bearing the oldest leaf, L-1, and a shoot primordium) and the apical shoot. If this shoot primordium is finally released, which can be monitored by appearance of L-5, a new lateral shoot will arise (Fig. 6).

$Z$. noltii is a fast growing species that colonizes the space using the "phalanx" strategy (sensu Lovett-Doust 1981). During the principal growing season (springsummer), the main rhizomes of $Z$. noltii (upto 11 internodes) branch in almost each node and usually develop upto quaternary axes (Brun et al. 2003b). Figure 7 represents the hypothetical topologies of a clonal network of $Z$. noltii during its growing season. The highest colonizing efficiency (measured as the largest area colonized and occupied with the same investment in rhizomes) and clone spreading $\left(\mathrm{m}^{2}\right.$ of area covered $\mathrm{m}^{-1}$ of rhizome) were achieved in Fig. 7c, which is the opposite pattern to that described in this study. In contrast, the lowest value was achieved in Fig. 7b, where an angle of $45^{\circ}$ and a "natural" branching pattern were simulated (i.e. shoot branches in the opposite direction to the previous one). The "natural" branching pattern allows a high colonizing efficiency to $Z$. noltii, but ca. $10 \%$ lower than that observed in the opposite pattern. However, changes in the branching angle caused larger effects on colonizing efficiency $(\approx 25 \%)$ than that recorded for the opposite branching pattern $(\approx 12 \%)$.

\section{Discussion}

Seagrasses exhibit clonal growth throughout the regular addition of units. Node, internode, roots, axillary shoot, sheath and a leaf constitute the "basic unit" of the clonal growth in Z. noltii. Analogous shoot organization has been described in land grasses, where 


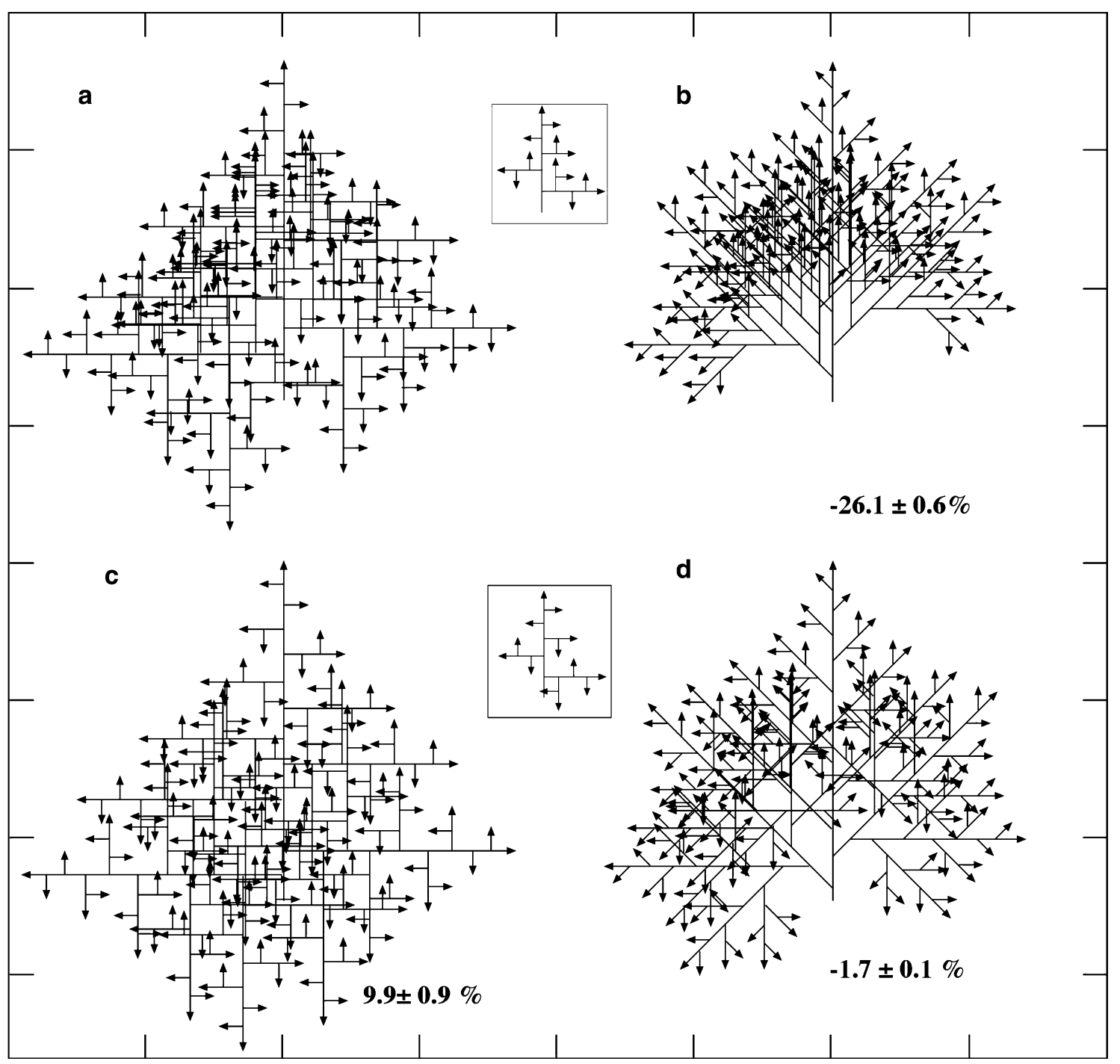

Fig. 7 Z. noltii. Plant clonal topology of $Z$. noltii plants using a the branching pattern recorded in this paper (i.e. "natural branching") and a branching angle of $90^{\circ}, \mathbf{b}$ the branching pattern recorded in this paper and a branching angle of $45^{\circ}$, $\mathbf{c}$ the opposite branching pattern recorded in this paper and a branching angle of $90^{\circ}, \mathbf{d}$ the opposite branching pattern recorded in this paper and a branching angle of $45^{\circ}$. All figures are constructed using 11 nodes and branches from the second one. The numbers indicate the reduction (negative values) or increment (positive values) in the area occupied in comparison with (a). The inset figures indicate the "natural branching" (a, b) and "opposite branching" (c, d) pattern. See text for further information the "basic units" (called "phytomer") are linked in sequential arrangements (called "tiller") and further interconnected to give the morphological structure (i.e. plant form) (Briske 1991; Nelson 2000).

Previous studies in Z. noltii (Brun et al. 2003b) and in other seagrass species (see Dalla et al. 1998; Tussenbroek et al. 2000) pointed out that the meadow structure and the relative abundance of the different shoot types (apical, lateral and single small) depended on the light availability that also drove interchanges among shoot types. The present study shows that differences among shoot categories are determined by two factors: (1) the presence or absence of some of the fundamental parts in the "phytomer" (mainly shoot primordium), (2) the evolvement stage of these elements. Therefore, it was hypothesised that Z. noltii, and probably the majority of seagrasses, can adjust to the environment through changes in timing of axillary shoot development and/or success in axillary shoot release. Measuring the PIs of the different shoot types can monitor such changes. Bud release in land plants proceeds in three stages: (1) bud development from a meristem, (2) activation and progression into a visible leaf and (3) environmental suitability to ensure survival and growth (Tomlinson 1974; Nelson 2000). Accordingly, Porter (1985) and Nelson (2000) reported that the release of the axillary bud at node $n$ seemed to be co-ordinated with the stage when cell division stops in the sheath at the same node (axillary bud formed by phytomer $n+1$ ). If the axillary bud misses these windows, the probability of its release 
at each new window was markedly reduced. Hence, large differences between PI-A and PI-5 (plastochrone interval for L-5) will determine that shoot primordium does not get released. Alternatively, also these large differences may cause shoot primordium to evolve into the sediment without the protection of oldest sheath (L1), since internode between L-1 and L-5 will grow. The later has been often observed in the seagrasses $Z$. noltii and Cymodocea nodosa during field samplings when L-5 developed without the protection of the oldest sheath. A minimum development of an etiolated L-5 (upto $5 \mathrm{~mm}$ ) and without any new leaves in the axillary shoot has been recorded (F. G. Brun, personal observation). This is mainly because meristems and axillary shoots are buried in the sediment at variable depths depending on the local environmental conditions (Brun et al. 2005; Duarte et al. 1998; Marbá and Duarte 1998). Furthermore, the sediment is frequently hypoxic or anoxic, and contains bacterial-derived phytotoxic compounds (sulphide, methane, ammonium and volatile organic acids) (Holmer and Nielsen 1997; Terrados et al. 1999; Enríquez et al. 2001) that may reduce axillary shoot and meristem survival preventing plant branching and affecting the overall growth (Carlson et al. 1994; Armstrong et al. 1996a, b; Armstrong and Armstrong 2001; Brun et al. 2002; Greve et al. 2003). Physical abrasion by sediment particles can also damage axillary shoots and meristems. Therefore, the sheath of the oldest leaf (frequently total or partially buried in the sediment) would prevent or, at least, diminish the physical and chemical damage suffered by axillary shoots and newly formed leaves, since the leaf sheath encloses them. The lack of porous and lignified cell walls of leaf sheath would contribute to improve its protective and "isolating" role, reducing the entry of certain solutes (Kuo and Cambridge 1978; Barnabas 1989; Tyerman 1989).

This study shows that shoot activation or inhibition can be forecasted by monitoring the appearance of L-5. The emergence of a L-5 in the apical shoot will determine the appearance of a new lateral shoot in the node. However, it is presumed that if the same process (i.e. development of a new lateral shoot) takes place in a lateral or single small shoot (i.e. vertical shoot for larger species), it will determine the branching of this shoot. In land plants, mainly for grasses and cultivable species a "leaf appearance" approach is used to determine the branch appearance. For example, in some models for cereal crop growth and grassland spreading, branching is calculated from the leaf appearance rate of the mainstream (Neuteboom and Lantinga 1989; Bone et al. 1990; Bos and Neuteboom 1998). Accordingly, combinations among PIs could be useful to elucidate intra- and inter-specific architectural differences. The PI-A/PI-5 index (plastochrone interval for apical shoot and for L-5) would determine the likelihood of lateral shoots being produced at each node (Table 1; Fig. 8), whereas PI-L/PI-5 (plastochrone interval for lateral/vertical shoot and for L-5) would determine the fate of the shoot produced (i.e. to branch or to become a vertical shoot) (Table 1). This hypothesis was checked by comparing the architecture of several seagrass species with the values for the cited indexes derived from Duarte (1991) under the following assumptions: (1) shoot plastochrone interval (SPI) was equivalent to PI-5, since PI-5 determines the appearance of a lateral shoot. (2) Leaf plastochrone interval (LPI) corresponded to PI-L and (3) rhizome plastochrone interval (RPI) was equivalent to $P I-A$, since internode growth takes place during one $P I-A$. Fig. 8 shows the correlation between the $P I-A / P I-5$ index and the number of shoots per rhizome internode (SPI), using data derived from Duarte (1991) and the assumptions outlined previously. Unfortunately, data on branching frequency are limited (Marbá and Duarte 1998) precluding the exploration of the relationship between the $P I-L / P I-5$ index and branching frequency, which will deserve future research efforts. When $P I-A$ / $P I-5$ and $P I-L / P I-5$ were lower than 0.25 , the clone architecture was nearly linear, with very few lateral shoots developed (finally becoming in vertical shoots) and rather infrequent branching (e.g. Amphibolis antarctica, Posidonia oceanica and Thalassia hemprichii). When indexes varied between 0.25 and 0.5 , clones developed some lateral shoots with occasional branches (e.g. Cymodocea serrulata, Enhalus acoroides, T. testudinum, Z. marina). Values upto 1.0 determined shoot appearance at the majority of nodes and branching ( $C$. nodosa, Halodule uninervis), whereas values higher than 1.0 determined shoot development at every node and the

Table 1 Different combinations of plastochrone intervals $(P I S)$ with the suggested seagrass architectural outcome. $P I-A, P I-L, P I-5$ plastochrone intervals for apical, lateral shoots and L-5, respectively

\begin{tabular}{llll}
\hline PI Interval & Implication & Value & Architectural outcome \\
\hline PI-A/PI-5 & Would determine the probability & $<0.25$ & Sporadic (very improbable) \\
& of producing a new lateral & $0.25-0.5$ & Occasional (infrequent) \\
& shoot in the main rhizome & $0.5-1.0$ & Regular \\
& $>1.0$ & At every node \\
$P I-L / P I-5$ & Would determine the fate & $<0.25$ & Vertical shoots, branching very improbable \\
& of the produced lateral shoots, & $0.25-0.5$ & Vertical shoots, occasionally branching \\
& that is, branching or vertical growth & $0.5-1.0$ & Vertical and lateral shoots and regular branching \\
& $>1.0$ & High probability of branching at every node \\
\hline
\end{tabular}

Further explanations are given in the text and in Fig. 8 
Fig. 8 Correlation between the number of shoots per rhizome internode $(S P I)$ and $P I-A / P I-5$ index in 14 seagrass species. Data were modified from Duarte (1991). Letters inserted indicate the species: $A a$

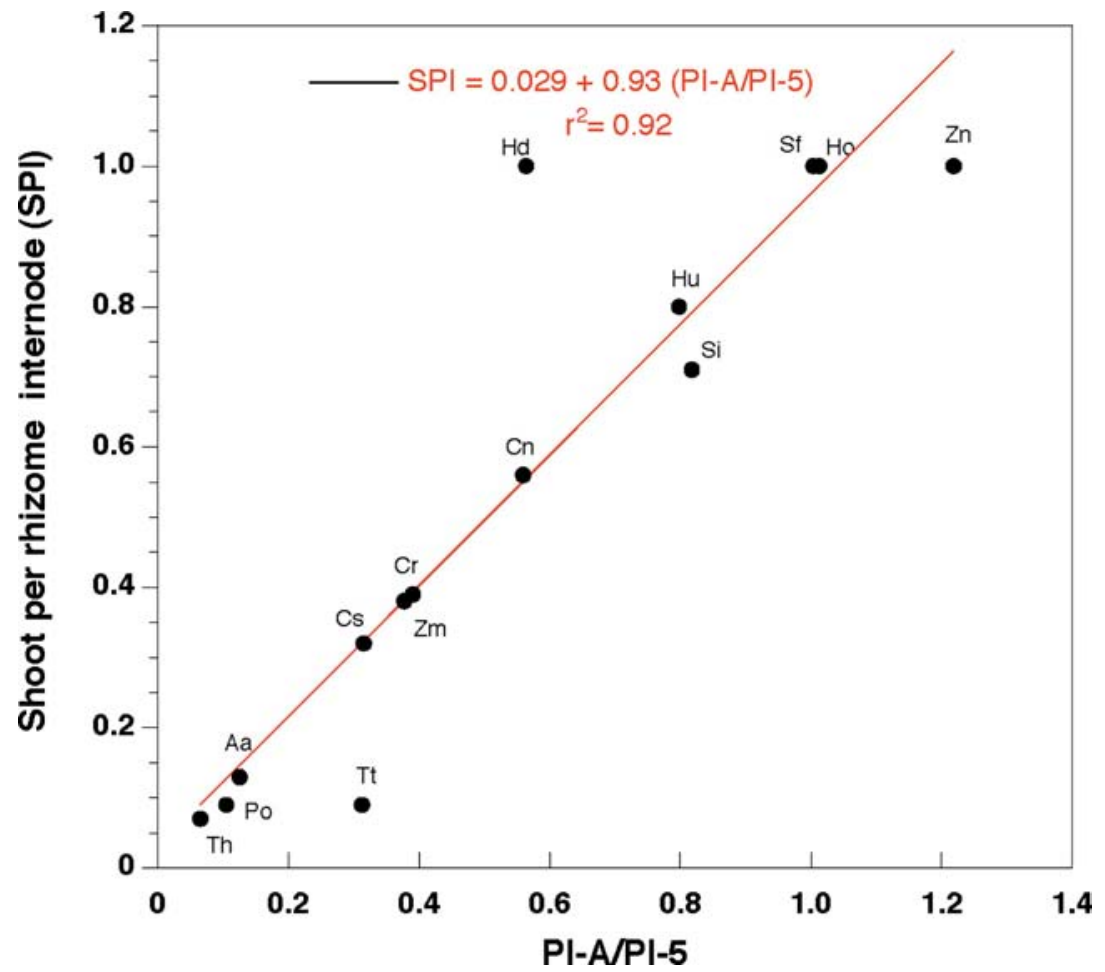

highest branching (Halophila decipiens, H. ovalis, Syringodium filiforme, $S$. isotifolium, $Z$. noltii). Besides the inter-specific differences in PIs, intra-specific variations have also been recorded driven by environmental factors (Peralta et al. 2000, 2002, 2003; Brun et al. 2002, 2003a, c). Therefore, the clonal traits (imprinted in the genome and accounting for the plant architecture, productivity, clone spreading and space occupation strategies) could be obtained if different combinations between PIs are considered.

This study showed that the branching angle and pattern are crucial factors to determine the colonizing efficiency and clone spreading in seagrasses. However, this study also established that while branching pattern is a species-specific trait that cannot be modified, branching frequency and angle can vary (Marbá and Duarte 1998; F. G. Brun et al., unpublished). This suggests that shoot arrangement may allow seagrasses to optimize the colonizing strategy with respect to abiotic conditions (light, nutrients, density, etc.) through changes in the branching angles and frequency, and direct experimental data are needed to test this hypothesis.

In conclusion, $Z$. noltii shoots are arranged by a successive repetition of a "basic unit" composed of leaf, sheath, axillary shoot, node, roots and internode resembling that described for land grasses called "phytomer". The branching pattern is constrained by shoot organization, that is, the first axillary shoot branches in the opposite direction to the previous branch. Shoot organization makes $Z$. noltii able to adjust to the environment through three different strategies: (1) changes in the branching angle, (2) timing of shoot development and/or (3) success in shoot releases. The study of the variations in PIs can be an useful tool to understand the species-specific architectural traits and the response of seagrasses against environmental constraints.

Acknowledgements This study has been supported by the project REN2002-00746 from the Ministerio de Ciencia y Tecnología (MCYT). The authors would like to thank to Juanma Brun for his microscopy help, to Juan Miguel Mancera for his laboratory assistance, and specially to Agustín Santos for the histological sections. F.G. Brun holds a Marie Curie fellowship from the European Commission. A. Pérez-Pastor hold a grant from the Ministerio de Ciencia y Tecnología.

\section{References}

Armstrong J, Armstrong W (2001) An overview of the effects of phytotoxins on Phragmites australis in relation to die-back. Aquat Bot 69:251-268

Armstrong J, Armstrong W, VanderPutten WH (1996a) Phragmites die-back: Bud and root death, blockages within the aeration and vascular systems and the possible role of phytotoxins. New Phytol 133(3):399-414

Armstrong J, Armstrong W, Wu ZB, AfreenZobayed F (1996b) A role for phytotoxins in the Phragmites die-back syndrome? Folia Geobot Phytotx 31(1):127-138

Bancroft JD, Stevens A (eds) (1990) Theory and practice of histological techniques 3rd edn. Churchil Livingstone. Medical division of Longman Group UK limited, New York, pp 726

Barnabas AD (1989) Apoplastic tracer studies in the leaves of a seagrass. II. Pathway into leaf veins. Aquat Bot 35:375-386

Berleth T, Sachs T (2001) Plant morphogenesis: long distance coordination and local patterning. Curr Opin Plant Biol 4:57-62

Bone MYL, Rickman RW, Whisler FD (1990) Leaf appearance of two winter wheat cultivars under high carbon dioxide conditions. Agron J 82:141-149 
Bos HJ, Neuteboom JH (1998) Morphological analysis of leaf and tiller number dynamics of wheat (Triticum aestivum L): responses to temperature and light intensity. Ann Bot 81:131-139

Briske DD (1991) Developmental morphology and physiology of grasses. In: Heitschmidt RK, Stuth JW (eds) Grazing management: an ecological perspective. Timber Press, Portland, pp 85-108

Brouns JJWM (1987a) Aspect of production and biomass of four seagrass species (cymodoceoideae) from Papua New Guinea. Aquat Bot 27:333-362

Brouns JJWM (1987b) Growth patterns in some indo-west-pacific seagrasses. Aquat Bot 28:39-61

Brun FG, Vergara JJ, Hernández I, Pérez-Lloréns JL (2003a) Growth, carbon allocation and proteolytic activity in the seagrass Zostera noltii shaded by Ulva canopies. Funct Plant Biol 30(5):551-560

Brun FG, Pérez-Lloréns JL, Vergara JJ, Hernández I (2003b) Patch distribution and within-patch dynamics of the seagrass Zostera noltii Hornem at Los Toruños salt-marsh (Cádiz Bay, Natural Park, Spain). Bot Mar 4(6):513-524

Brun FG, Vergara JJ, Navarro G, Hernández I, Pérez-Lloréns JL (2003c) Effect of shading by Ulva rigida canopies on growth and carbon balance of the seagrass Zostera noltii. Mar Ecol Prog Ser 265:85-96

Brun FG, Vergara JJ, Hernández I, Peralta G, Pérez-Lloréns JL (2002) Assessing the toxicity of ammonium pulses in the survival and growth of Zostera noltii Hornem. Mar Ecol Prog Ser 225:177-187

Brun FG, Hernández I, Pérez-Lloréns JL, Vergara JJ (2005) Evidence for vertical growth in Zostera noltii Hornem. Bot Mar (in press)

Carlson PR, Yarbro LA, Barber TR (1994) Relationship of sediment sulfide to mortality of Thalassia testudinum in florida bay. B Mar Sci 54(3):733-746

Dalla Via J, Sturmbauer C, Schönweger G, Sötz E, Mathekowitsch S, Stiffer M, Rieger R (1998) Light gradients and meadow structure in Posidonia oceanica: ecomorphological and functional correlates. Mar Ecol Prog Ser 163:267-278

Den Hartog C (1970) The seagrasses of the world. North-Holland Co, Amsterdam, pp 275

Duarte CM (1991) Allometric scaling of seagrass form and productivity. Mar Ecol Prog Ser 67:201-207

Duarte CM, Merino M, Agawin NSR, Uri J, Fortes MD, Gallegos ME, Marbá N, Hemminga M (1998) Root production and belowground seagrass biomass. Mar Ecol Prog Ser 171:97-108

Duarte CM, Sand-Jensen K (1990) Seagrass colonisation: patch formation and patch growth in Cymodocea nodosa. Mar Ecol Prog Ser 65:193-200

Enríquez S, Marbá N, Duarte CM, van Tussenbroek B, Reyes G (2001) Effects of seagrass (Thalassia testudinum) on sediment redox. Mar Ecol Prog Ser 219:149-158

Evans MSM, Barton K (1997) Genetics of angiosperm shoot apical meristem development. Ann Rev Plant Phys Plant Mol Biol 48:673-701

Greve TM, Borum J, Pedersen O (2003) Meristematic oxygen variability in eelgrass (Zostera marina). Limnol Oceanogr 48(1):210-216

Hemminga MA, Duarte CM (2000) Seagrass ecology. Cambridge University Press, Cambridge, pp 298

Holmer M, Nielsen SL (1997) Sediment sulfur dynamics related to biomass-density patterns in Zostera marina (eelgrass) beds. Mar Ecol Prog Ser 146:163-171

Kuo J, Cambridge ML (1978) Morphology, anatomy and histochemistry of the Australian seagrasses of the genus Posidonia
König (Posidoniaceae). II. Rhizome and root of Posidonia australis Hook F. Aquat Bot 5:191-206

Lovett-Doust L (1981) Population dynamics and local specialization in a clonal perennial (Rannunculus repens). The dynamics of ramets in contrasting habitats. J Ecol 69:743-755

Marbà N, Duarte CM (1998) Rhizome elongation and seagrass clonal growth. Mar Ecol Prog Ser 174:269-280

Molenaar H, Barthélémy D, de Reffye P, Meinesz A, Mialet I (2000) Modelling architecture and growth patterns of Posidonia oceanica. Aquat Bot 66:85-99

Nelson CJ (2000) Shoot morphological plasticity of grasses: leaf growth vs tillering. In: Lemaire $\mathrm{G}$, Hodgson J, de Moraes A, Nabinger C, Carvalho PCF (eds) Grassland ecophysiology and grazing ecology. CAB International, pp 101-126

Neuteboom JH, Lantinga EA (1989) Tillering potential and relationship between leaf and tiller production in perennial ryegrass. Ann Bot 63:265-279

Peralta G, Pérez-Lloréns JL, Hernández I, Vergara JJ (2002) Effects of light availability on growth, architecture and nutrient content of the seagrass Zostera noltii Hornem. J Exp Mar Biol Ecol 269:9-26

Peralta G, Bouma TJ, van Soelen J, Pérez-Llorens JL, Hernandez I (2003) On the use of sediment fertilization for seagrass restoration: a mesocosm study on Zostera marina L. Aquat Bot 75:95-110

Peralta G, Pérez-Lloréns JL, Hernández I, Vergara JJ, Bartual A, Brun FG, Gálvez JA, García CM (2000) Morphological and physiological differences of two morphotypes of Zostera noltii Hornem. from the southwestern Iberian Peninsula. Helgol Mar Res 54:80-86

Pérez-Lloréns JL, Brun FG, Andría J, Vergara JJ (2004) Seasonal and tidal variability of environmental carbon related physico-chemical variables and inorganic $\mathrm{C}$ acquisition in Gracilariopsis longissima and Enteromorpha intestinalis from Los Toruños salt marsh (Cádiz Bay, Spain). J Exp Mar Biol Ecol 304:183-201

Porter JR (1985) Approaches to modeling canopy development in wheat: In: Day W, Atkin RK (eds) Wheat growth modeling. Plenum Press. New York, pp 69-81

Slade AJ, Hutchings MJ (1987) Clonal integration and plasticity in foraging behaviour in Glechoma hederacea. J Ecol 75:10231036

Sussex IM, Kerk NM (2001) The evolution of plant architecture. Curr Opin Plant Biol 4(1):33-37

Terrados J, Duarte CM, Kamp-Nielsen L, Borum J, Agawin NSR. Fortes MD, Gacia E, Lacap D, Lubanski M, Greve T (1999) Are seagrass growth and survival affected by reducing conditions in the sediment? Aquat Bot 65:175-197

Tyerman SD (1989) Solute and water relationship of seagrasses. In: Larkum AWD, McComb AJ, Shepherd SA (eds) Biology of seagrasses. Elsevier, Amsterdam

Tomlinson PB (1974) Vegetative morphology and meristem dependence. The foundation of productivity in seagrasses. Aquaculture 4:107-130

Tomlinson PB, Posluszny U (1978) Aspects of floral Morphology and development in the seagrass Syringodium filiforme (Cymodoceaceae). Bot Gaz 139(3):333-345

Tomlinson PB (1982) Helobiale (Alismatidae). In: Metcalfe CR (eds) Anatomy of the monocotyledons: VII. Clarendon Press, Oxford, pp 559

Tussenbroek van BI, Galindo GA, Marquez J (2000) Dormancy and foliar density regulation in Thalassia testudinum. Aquat Bot 68:281-229 